\title{
Educando en la frontera norte de Chile: El patrimonio cultural desafiando la exclusión social
}

\section{Educating in the northern border of Chile: Cultural heritage challenging social exclusion}

Jair Marín-Alaniz*a (1D) https://orcid.org/0000-0001-9062-8333
Recibido el 15 de mayo de 2018. Aceptado el 8 de noviembre de 2018. Publicado el 3 de diciembre de 2018.

*Autor para correspondencia: Jair Marín-Alaniz, correo electrónico: jair.marin.alaniz@gmail.com

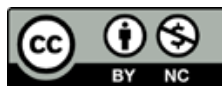

Esta obra está protegida bajo una Licencia Creative Commons Atribución-NoComercial 4.0 Internacional. a Universidad Arturo Prat, Instituto de Estudios Andinos Isluga, Chile, correo electrónico: jair. marin.alaniz@gmail.com

\section{Resumen}

El objetivo de este artículo es comprender el contexto de exclusión social que enfrentan los niños y niñas de las familias migrantes que residen en Chile, así como el uso del patrimonio cultural inmaterial que utilizan en los espacios escolares para avanzar hacia la inclusión social. Desde una metodología cualitativa, la muestra fue integrada por profesores y un equipo psicosocial, quienes trabajan en una escuela pública. La técnica empleada para la recolección de información fue el grupo focal y para el análisis de los datos se utilizó el análisis de contenido. Los resultados revelan una geografía de la exclusión social que se expresa en el contexto barrial, laboral y escolar. Sin embargo, se identifica también la valoración del patrimonio cultural inmaterial como herramienta para avanzar hacia la inclusión social.

Palabras clave: migración, escuela, exclusión social, patrimonio cultural inmaterial.

\section{Abstract}

The objective of this article is to understand the context of social exclusion faced by children of migrant families residing in Chile, as well as the use of intangible cultural heritage that they use in school spaces to advance towards social inclusion. From a qualitative methodology, the sample was integrated by professors and psychosocial team who work in a public school. The technique used for the collection of information was focus group. Content analysis was used to analyze the data. The results reveal a geography of social exclusion expressed in the neighborhood, work and school context. However, valuation of intangible cultural heritage is also identified as a tool to move towards social inclusion.

Keywords: migration, school, social exclusion, intangible cultural heritage.

CÓMO CITAR: Marín-Alaniz, J. (2018). Educando en la frontera norte de Chile: El patrimonio cultural desafiando la exclusión social [Educating in the northern border of Chile: Cultural heritage challenging social exclusion]. Estudios Fronterizos, 19, e019. doi:https:// doi.org/10.21670/ref.1819019 


\section{Introducción ${ }^{1}$}

En Chile, la Política Nacional de Niñez y Adolescencia 2015-2025 corresponde al resultado de un proceso de formulación participativa en el que colaboraron el Estado, la sociedad civil, los niños y niñas, y adolescentes del país. En esta línea, son cinco los enfoques que sustentan esta política nacional: derechos, desarrollo humano, curso de vida, género e intercultural. Este último enfoque reconoce que las personas de origen indígena y migrantes necesitan medidas especiales para el cumplimiento de sus derechos individuales y colectivos, sin discriminación y en igualdad de condiciones que el resto de la población (Consejo Nacional de Infancia, 2015 p. 60).

Este reconocimiento de la diversidad cultural posee una estrecha relación con las estadísticas oficiales, las que señalaban que en el año 2014 residían en el país cerca de 411000 personas extranjeras, provenientes principalmente de países sudamericanos como: Perú, Argentina, Bolivia, Colombia y Ecuador (Departamento de Extranjería y Migración del Ministerio del Interior y Seguridad Pública, 2016). Este proceso se clasifica como migración intrarregional, que considera los desplazamientos entre todos los países latinoamericanos, sobrepasando el carácter fronterizo y regional (Durand, 2013).

Fue al inicio de la década de 1990 cuando el proceso de la migración intrarregional se intensificó gracias a la liberalización del tránsito, el comercio y el turismo. Los procesos de integración económica han facilitado la gestión de los trámites migratorios, al punto que los sudamericanos, en la actualidad, pueden viajar por la región sin visa y en algunos casos sin la necesidad de pasaporte, ya que únicamente se les solicita presentar un documento nacional de identidad (Durand, 2013, p. 62).

En este contexto, el posicionamiento de Chile como un destino para la migración intrarregional se explica por la imagen positiva de su estabilidad económica e institucional, lo cual ha construido la idea del denominado "sueño chileno" entre los migrantes que ingresan al país. Además, debemos considerar el incremento de las barreras de ingreso establecidas luego de la última crisis económica mundial, en las fronteras de los destinos convencionales como Estados Unidos y los países europeos (Tapia, 2014, p. 37).

Junto a la capital, las ciudades ubicadas en la frontera norte del país concentran un gran número de población migrante. Gracias al desarrollo de la industria de la minería y el comercio internacional, estimulado por su condición de puerto, la norteña ciudad fronteriza de Iquique constituye uno de los principales centros urbanos receptores de migrantes. Su carácter multicultural se debe además a la herencia cultural del pueblo aymara, cuya influencia se extiende por Perú, Bolivia y el norte de Chile.

Ahora bien, la inserción de las familias migrantes en la sociedad chilena está evidenciando situaciones de exclusión social y discriminación, las cuales se relacionan con la informalidad laboral, la degradación de los barrios como consecuencia del hacinamiento de las viviendas, y las carencias generales del sistema sanitario y educativo.

\footnotetext{
${ }^{1}$ Artículo escrito para la obtención del grado de Magíster en Patrimonio Intangible, Sociedad y Desarrollo Territorial. Proyecto "Puesta en valor digital y formación del capital humano, para el patrimonio intangible de Tarapacá", financiado por el Fondo de Innovación para la Competitividad (FIC) del Gobierno Regional de Tarapacá y ejecutado por el Instituto de Estudios Andinos Isluga de la Universidad Arturo Prat (www. tarapacaenelmundo.cl).
} 
Centrando la mirada en la infancia, Pavez (2012) ha abordado la experiencia de la niñez peruana en Santiago de Chile poniendo en evidencia la vulneración de los derechos de la infancia. Tijoux (2013) ha profundizado sobre el racismo en el contexto escolar y propone una educación contra el mismo. Riedemann y Stefoni (2015) han identificado una negación del racismo y sus consecuencias para una educación antirracista en la enseñanza secundaria. Joiko y Vásquez (2016, p. 167) sostienen que los contextos escolares sensibilizados con la temática migratoria se encuentran en un estado de integración más que de inclusión, por lo que insisten en la necesidad de una mayor reflexión sobre el concepto de inclusión y en cómo este se vincula con la interculturalidad. Por último, en el contexto específico de la frontera norte de Chile, algunos autores han explorado las difíciles condiciones de vida que enfrentan las familias migrantes (Marín, 2014), así como las características generales que distinguen el proceso de ingreso de los estudiantes migrantes en las escuelas fronterizas (Mondaca, Gajardo, Muñoz, Sánchez y Robledo, 2015). Estos antecedentes dan sustento y urgencia a la Política Nacional de Niñez y Adolescencia 2015-2025, pues a partir de su enfoque intercultural busca establecer las condiciones para la construcción de una sociedad más inclusiva e igualitaria (Consejo Nacional de Infancia, 2015). Al revisar la literatura internacional, Marxen (2011, p. 155) también rescata el valor del intercambio cultural en el ámbito educativo, señalando que el trabajo artístico puede ayudar a integrar los elementos biculturales que facilitan una mayor inclusión entre los niños. Frente a este escenario, aparece el patrimonio cultural inmaterial como una herramienta para reconocer el aporte de las culturas migrantes.

Por lo anterior, el objetivo de este artículo es comprender la geografía de la exclusión social en la que resisten los estudiantes que pertenecen a familias migrantes que se han establecido en la frontera norte de Chile, así como el uso del patrimonio cultural inmaterial que utilizan en los espacios escolares para alcanzar la inclusión social. Para ello, en un primer momento se presenta una breve revisión de dos conceptos teóricos que orientan el estudio: geografía de la exclusión social y patrimonio cultural inmaterial. Luego se describe la metodología utilizada y los hallazgos alcanzados. Por último, se presentan las conclusiones para avanzar hacia una mayor comprensión de este proceso en las escuelas chilenas.

\section{Marco Teórico}

\section{Geografía de la exclusión social}

Jiménez (2008, p. 178) define la exclusión social como un proceso multidimensional, que tiende a acumular, combinar y separar, tanto a individuos como a colectivos, de los derechos sociales tales como el trabajo, la educación, la salud, la cultura, la economía y la política. Derechos a los que otros colectivos sí tienen acceso, anulando así el concepto de ciudadanía. Ahora bien, Arias y Campos (2011, p. 2) sostienen que bajo cualquier definición que se quiera hacer al respecto, existe una dimensión territorial que la condiciona y profundiza. Así, analizan la pobreza urbana a partir de la descripción de una geografía de "desventajas", tomando como referentes dos espacios claves de socialización dentro de la ciudad: el barrio y la escuela. De este modo intentan definir una "geografía de la exclusión socio-espacial", la que funciona por un lado como una 
condición estructural del territorio, y por otro, como una constante recreación de prácticas sociales de exclusión.

Centrando la atención en los migrantes, es justamente la exclusión social expresada en las crisis económicas, las guerras o las persecuciones políticas (Tijoux, 2011, p. 38) la que los obliga a dejar sus países. No obstante, la migración no garantiza alcanzar la anhelada inclusión social, por el contrario, desde su inicio impone múltiples barreras para lograrla.

Si bien la migración implica la movilidad de un espacio a otro, las fronteras internacionales representan un punto inmovilizante filtrando lo que puede salir o entrar, operando entonces un sistema de legalidad-ilegalidad (Benedetti y Salizzi, 2011, p. 61). Si logran sortear los procedimientos en los recintos fronterizos, los migrantes se asientan en las ciudades de destino. Sin embargo, las ciudades poseen configuraciones territoriales que construyen espacios de exclusión donde las dinámicas sociales limitan el acceso igualitario a las oportunidades (Arias y Campos, 2011, p, 4). Algunas denominaciones como barrio étnico y gueto (Torres, 2011), barrios de migrantes (Sassone y Mera, 2007) o zonas de transición (Guizardi, 2013) intentan dar cuenta de la segregación que distinguen a las concentraciones urbanas donde se ubican los migrantes.

En este escenario, las escuelas también se alzan como territorios fundamentales para comprender la geografía de la exclusión social, pues la segregación escolar concentra a los estudiantes en condición de vulnerabilidad en las escuelas que se localizan en unidades territoriales particulares (Arias y Campos, 2011, p. 6); de esto también da cuenta Marín (2014) en su estudio con familias migrantes en la frontera norte de Chile.

De igual modo, en el ámbito del trabajo, los migrantes enfrentan una segmentación que limita sus alternativas laborales, estimulando la creación de estereotipos negativos (Stefoni, 2002). En esto inciden las transformaciones económicas capitalistas, las subjetividades provocadas por el neoliberalismo y la construcción política del temor al otro, transmitida a través de los medios de comunicación. Como trabajadores precarios, los migrantes compiten en condiciones de mayor explotación y menores salarios (Tijoux, 2011, p. 38). Sobre estos aspectos han ahondado Rojas y Vicuña (2014) en su estudio y propuesta para la inclusión sociolaboral de los migrantes en la ciudad fronteriza de Arica.

En estos territorios de exclusión, aflora la discriminación social que se define como toda distinción que provoca un daño, humillación o perjuicio en la dignidad de una persona y que no tiene causa racionalmente justificable. Estas distinciones se basan, entre otras, en condiciones como: origen étnico o nacional, género, discapacidad, edad, religión, condiciones de salud, orientación sexual, situación económica o social (Soberanes, 2010, p. 263).

Volviendo la mirada a los procesos migratorios, destaca la discriminación por el color de la piel. Aparece entonces el "cuerpo", pues devela su origen y con ello una etnia, un país y un color de piel (Tijoux, 2011, p. 33). Con el cuerpo se transita por la geografía de la exclusión social constituyéndose como un sello o marca permanente:

Un cuerpo-problema para la existencia actual, construida en torno al culto del individuo que triunfa al compás de cánones fijados por un neoliberalismo triunfante que lo despoja de la individualidad que lo hace ser único, y que exige un cuerpo forjado en ideales universales armados en torno al origen y las características aceptables del cuerpo. 
El cuerpo es "sentido" como algo identificado y hecho público, es el revés del "nosotros" y es justamente esta "otredad" la que ayuda a que se construyan procesos de formación racial. Más aún cuando el racismo, que hemos visto puede ser entendido como valoración de las diferencias, termina por legitimar actos o discursos violentos contra estos inmigrantes que quedan expuestos por la marca entera "que es" su propio cuerpo (Tijoux, 2011, p. 33).

Por tanto, los migrantes deben resistir en la geografía de la exclusión social que se encuentra plagada de fronteras. El barrio, el trabajo o la escuela, suponen espacios complejos de habitar, donde las características corporales definen la ubicación dentro del sistema social. El cuerpo como "frontera" representa así una "otredad" difícil de incluir.

\section{Patrimonio cultural inmaterial}

El término Patrimonio de la Humanidad nació en 1972, en la "Convención para la protección del patrimonio mundial cultural y natural" de la Organización de las Naciones Unidas para la Educación, la Ciencia y la Cultura (Unesco). A nivel general se entiende que el patrimonio integral de un territorio lo componen los objetos naturales y los objetos materiales culturales, pero además lo componen los comportamientos, saberes y valores de quienes lo habitan. Esto último corresponde al patrimonio cultural inmaterial que comprende tradiciones heredadas de los antepasados y transmitidas a las nuevas generaciones, destacando entre ellas las tradiciones orales, las artes del espectáculo, los usos sociales, los rituales, las fiestas, los saberes y las técnicas asociadas a la artesanía (Olivera, 2011, p. 664).

Durante la década de 1990 la Unesco inició el programa de Patrimonio cultural inmaterial, cuyos principios eran la revitalización y la transmisión de las prácticas culturales como estrategias para su protección. En la misma línea, en el año 2002 el organismo llevó a cabo la Reunión de Expertos en Terminología, con el objetivo de crear un glosario de términos para el instrumento normativo internacional. Surgió entonces el término "portadores de cultura" para designar a aquellos miembros de una comunidad que de manera activa reproducen, transmiten, transforman, crean y forman cultura. Además, acentuó que los miembros de las comunidades practicantes son los encargados de decidir sobre las prácticas culturales que deben ser salvaguardadas, para evitar que personas externas se apropien de los recursos culturales de las comunidades (Villaseñor y Zolla, 2012, p. 78). Por último, la Convención para la Salvaguarda del Patrimonio Cultural Inmaterial del año 2003, ha sido de particular importancia porque estableció una definición que hasta la actualidad genera un cierto nivel de consenso:

Se entiende por patrimonio cultural inmaterial los usos, representaciones, expresiones, conocimientos y técnicas - junto con los instrumentos, objetos, artefactos y espacios culturales que les son inherentes-que las comunidades, los grupos y en algunos casos los individuos reconozcan como parte integrante de su patrimonio cultural. Este patrimonio cultural inmaterial, que se transmite de generación en generación, es recreado constantemente por las comunidades y grupos en función de su entorno, su interacción 
con la naturaleza y su historia, infundiéndoles un sentimiento de identidad y continuidad y contribuyendo así a promover el respeto de la diversidad cultural y la creatividad humana (Unesco citado en Olivera, 2011, p. 664).

Respecto a las migraciones, Olivera (2011, p. 674) destaca su carácter histórico y sostiene que la comprensión del patrimonio cultural inmaterial de diversas comunidades estimula el diálogo entre culturas y promueve el respeto hacia otros modos de vida. Así, el respeto a "los otros" requiere necesariamente la consideración y tolerancia de sus costumbres y expresiones culturales inmateriales. No obstante, a nivel escolar, Jiménez y Fardella (2015, p. 433) sostienen que la atención a la diversidad de inspiración inclusiva, también puede terminar por convertirse en un escenario que obliga a la renuncia del patrimonio y la herencia cultural de los alumnos migrantes. Esto puede ocurrir cuando las escuelas se basan en una adaptación unilateral como forma de integración. Por lo anterior, es importante abordar la relación entre las migraciones y el patrimonio cultural inmaterial como estrategia para favorecer la inclusión social.

Caba y Rojas (2014), en su estudio con la comunidad peruana residente en Santiago de Chile, dan cuenta de una estrategia de apropiación simbólica y uso de signos identitarios en los espacios públicos. Estas manifestaciones estimulan la reterritorialización de las prácticas culturales y le han permitido a la comunidad peruana alcanzar mayor visibilidad e inclusión social:

El sentimiento de pertenencia a una colectividad, la reivindicación de valores compartidos y la reproducción de un grupo social, hacen de esta experiencia un asunto central para la reapropiación simbólica posterior al desplazamiento. Al mismo tiempo, la reconstrucción colectiva tiene que ver con un complejo proceso de puesta en escena de los recursos de la memoria colectiva, así como el uso efectivo de ciertos referentes que permitan generar inclusión social y proyectar un futuro común. Es en ese sentido que migración, identidad y prácticas culturales, aglutinados y visibilizados a través del patrimonio cultural inmaterial, han sido el eje central de esta aproximación (Caba y Rojas, 2014, p. 111).

Por tanto, la práctica patrimonial no persigue reafirmar lo nacional, sino fomentar un contexto de integración recíproca, quebrando los imaginarios nacionalistas. La gastronomía, las danzas y la religiosidad popular, son movilizadas transnacionalmente, invitando al diálogo y al encuentro desde la diversidad, creando así condiciones necesarias para la igualdad sociocultural (Caba y Rojas, 2014, p. 112).

En el ámbito de la educación artística, Huerta y Domínguez (2013, p. 11) articulan el concepto de patrimonios migrantes, destacando la desubicación geográfica de los patrimonios como un valor que contribuye a la transición de saberes y al intercambio de ideas y planteamientos entre los educadores y el alumnado.

La educación patrimonial se intensifica gracias a esta novedosa contribución, ya que los patrimonios migrantes introducen la desubicación geográfica del engranaje patrimonial como elemento válido para la reflexión. Cuestiones clave como puedan ser las trashumancias, las herencias, las migraciones humanas, el tránsito de saberes entre profesorado y alumnado, el comercio de bienes, o las mutaciones del valor patrimonial, son aspectos válidos para relacionar activamente patrimonio con educación. Todo ello desde un 
posicionamiento flexible, que se intensifica al variar las ubicaciones. En una sociedad que fluye entre lo presencial y lo virtual debemos estar preparados para activar un patrimonio rico en migraciones (Huerta y Domínguez, 2013, p. 10).

En resumen, el patrimonio cultural inmaterial destaca por su capacidad de generar encuentros entre culturas, debilitando las fronteras y estimulando la inclusión social en los contextos transnacionales que surgen a partir de la migración intrarregional. Por tanto, las oportunidades para la inclusión social que presentan desde la promoción del patrimonio se pueden extender a toda la ecología social y en particular a las escuelas, que es donde se juega el destino de las comunidades.

\section{Metodología}

El estudio se realizó en una escuela pública de la ciudad de Iquique, la cual ha implementado un plan de acogida para las familias migrantes. Cabe destacar que este es uno de los establecimientos educacionales con mayor matrícula migrante en la frontera norte de Chile, puesto que se ubica en el sector comercial de la ciudad donde viven muchas familias migrantes. La escuela se distingue por su compromiso con las familias y las prácticas educativas orientadas a la inclusión de todos sus estudiantes. La investigación se basa en una metodología cualitativa que busca explicar y comprender las interacciones y los significados subjetivos de los individuos y los grupos (ÁlvarezGayou, 2003, p. 41).

Para la muestra se conformaron cuatro grupos focales compuestos por los agentes educativos: profesores y equipo psicosocial. Estos profesionales llevan años de trabajo atendiendo a familias migrantes. La opción de utilizar el grupo focal se sustenta en que es una técnica de investigación social que privilegia el habla, cuyo propósito es propiciar la interacción por medio de la conversación sobre un tema u objeto de investigación, en un tiempo determinado, y cuyo interés consiste en captar la manera de pensar, sentir y vivir de los individuos que conforman el grupo (Álvarez-Gayou, 2003, p. 132). El guion de las preguntas que orientaron los grupos focales fue inspeccionado por un par investigador que trabaja sobre la temática que aborda la investigación, utilizando la validez de experto. Los tópicos abordados en el guion del grupo focal fueron la geografía de la exclusión social en la que resisten los estudiantes de las familias migrantes que asisten a la escuela, así como el uso del patrimonio cultural inmaterial que utilizan para favorecer la inclusión social.

Para el análisis de los datos, se utilizó el análisis de contenido por su acercamiento a los postulados y procedimientos cualitativos y sus propósitos; también se acudió al criterio de saturación de datos para la definición de las categorías. Por último, para el resguardo de la confidencialidad de los participantes, se redactó un consentimiento informado donde se comunicaron los objetivos y alcances de la investigación y la protección de la privacidad a través de la eliminación de datos personales. 


\section{Resultados}

Para la presentación de los resultados se han considerado tres categorías: asuntos familiares, geografía de la exclusión social y valoración del patrimonio cultural inmaterial.

\section{Asuntos familiares}

Esta categoría posee un rol fundamental pues la familia se presenta como el eje articulador del proceso migratorio, se migra "por" y "con" la familia. Ahora bien, los adultos y en particular las mujeres, son quienes parten primero en busca de mejores oportunidades laborales. Con frecuencia los hijos permanecen en sus países de origen a la espera de que sus padres preparen las condiciones para la llegada del resto de la familia. Esta situación afecta directamente a los niños y niñas que en algunos casos quedan expuestos a situaciones de desprotección.

Nos llama la atención que mayoritariamente ella es quien se viene. Se vienen con la idea de estar un tiempo aquí, conseguir una estabilidad laboral, una habitación y traerse luego a los demás hijos. Pero a veces han roto el vínculo de la pareja y por lo tanto se han venido acá y no han firmado los papeles cuando terminaron con su pareja. Vienen y dicen: "¿cómo lo hago? no tengo ningún documento, el papá me niega el permiso para los niños”. También me ha tocado ver que se vienen con uno o dos niños pensando que acá en lo económico les va a ir bien y también luchan solas (trabajadora social, 2017).

El motivo principal que he recibido en los relatos de los alumnos, es el trabajo. El trabajo para ahorrar dinero, acá se dan cuenta que el costo de la vida es alto, porque arrendar una habitación también es caro, pero ellos trabajan con esa mentalidad, de que van a ahorrar unos años un dinero y que luego se van a regresar a su país. Allá tienen a veces terrenos o comparten casas con familias grandes, entonces ellos van ahorrando y mandando dinero a los hijos que dejan a cargo de otros familiares. También me ha tocado escuchar historias de vulneración en los países de ellos, a veces las madres están acá y sus familiares allá y con familiares de ellos mismos han ocurrido situaciones de abuso y cuando la madre se entera porque a veces la hija le cuenta, la madre la va a buscar (psicóloga, 2017).

Cuando la familia logra reunirse en Chile enfrenta nuevos desafíos asociados a la convivencia y la redistribución de los roles. La dinámica familiar establecida en los países de origen se ve desafiada por las presiones del nuevo contexto sociocultural, los años de separación, la incorporación de nuevos integrantes y el aplanamiento afectivo.

Ellas también a veces conocen a alguien aquí y comienzan una historia nueva, empiezan a organizarse con esa persona y los hijos se van teniendo que acomodar a esta nueva vida donde están los nuevos hermanos, pero ellos son como los recién llegados, entonces se empieza a acomodar una 
nueva estructura familiar, aquí a veces ocurren nuevos cambios como las separaciones que comenté (trabajadora social, 2017).

Hemos visto que la afectividad no está tan desarrolla en ellos, las mamás son más desapegadas y los hacen más independientes. Hay familias muy correctas en temas valóricos, la responsabilidad, cuando vienen son buenos estudiantes, pero en el tema afectivo parece que estuviera más plano, los padres se comunican con sus hijos pero no es un trato tan afectivo, tan de piel, sino de instrucciones, de órdenes, de enseñanzas de la vida a través de valores, de la responsabilidad. Las mamás a veces verbalizan que no tocan a sus hijos cuando uno les pregunta: "¿y usted es cariñosa?, usted podría abrazarlos porque ellos necesitan más afectividad". Ellas dicen: "no es que estamos acostumbrados, nosotros no somos así tan cercanos” (psicóloga, 2017).

Entre las tensiones socioculturales, los actores educativos identifican que para algunos padres migrantes el uso del castigo físico constituye una herramienta de crianza a la que acuden con frecuencia. Esta situación problematiza la relación entre las familias y la escuela, pues en Chile se está desarrollando un intenso debate respecto a cómo disminuir la violencia hacia los menores. El país comienza a tomar conciencia sobre la urgencia de abordar esta materia, y si bien las cifras de maltrato infantil son preocupantes, sí es claro que en el contexto escolar prevalece un discurso condenatorio ante la vulneración de los derechos de la infancia y se cuenta con dispositivos sociales específicos para promocionar el cuidado y bienestar de los estudiantes.

Las mismas mamás les cuentan a las profesoras: "sí tía, yo le pego porque si no él se pone rebelde", entonces es como algo que los mismos profesores trabajan en clases, respecto de los derechos de los niños, para educarlos en las leyes chilenas, donde siempre nuestro discurso es que los niños están por encima de todo, siempre la ley protege a los niños. Entendemos que traen sus maneras y formas de actuar o de criar, pero también ellos tienen que conocer cuáles son las nuestras, las que están permitidas, porque si ocurre lo que se acostumbra hacer allá, acá tendrían un problema, y si al niño le pegaban o en el colegio autorizaban a que lo golpearan, ese niño llega con un moretón aquí y nosotros lo vamos a llevar a constatar lesiones y luego a carabineros (psicóloga, 2017).

\section{Geografía de la exclusión social}

La economía chilena destaca por su estabilidad y apertura a los mercados internacionales, pero también por las desiguales oportunidades de desarrollo social que despliegan de su crecimiento. En este escenario, los migrantes también enfrentan numerosos espacios de exclusión social, similares a las que enfrentaban en sus países de origen y que justamente los instaron a partir. En el ámbito laboral se observan prácticas abusivas que llevan a la aceptación de trabajos mal remunerados y en ocasiones al ocultamiento de condiciones de explotación. 
Trabajan en oficios como meseras, haciendo aseo, cuidando niños, entonces generalmente tienen impedimentos porque no les quieren hacer contratos. Cuando yo les pregunto cuál es el horario en que los puedo citar, veo que tienen jornadas extensas y a veces en el mes tienen un día libre, no es como nosotros que trabajamos a lo más el sábado y tienes todo el domingo, ellos no, a veces tienen que acordar un día libre cada dos semanas. Visualizamos abusos económicos también que al final ellos para no perder el trabajo callan (trabajadora social, 2017).

A veces en sus jefes que tienen su misma nacionalidad, veo esa poca solidaridad en que regularicen sus papeles, facilitar las maneras para tener un contrato, por ejemplo cuando tienen que pedir permiso porque están citados en el colegio dicen: "no es que mi jefa no me deja, ella es muy estricta", y también es peruana como la misma señora peruana que tengo en frente, o las mismas señoras bolivianas (psicóloga, 2017).

Las largas jornadas laborales, junto con la participación en más de un trabajo, impide a los padres atender adecuadamente las necesidades de los hijos, quienes quedan solos o al cuidado ocasional de sus vecinos. Así, los hijos deben realizar labores de adultos y asumir roles parentales que los exponen a serias situaciones de estrés al asumir responsabilidades que lógicamente no están en condiciones de gestionar.

Las extensas jornadas de trabajo que hacen que los niños tengan que asumir roles de adultos, cuidar a los hermanos más pequeños, organizarse para hacer las labores de la casa y los padres con la mentalidad de trabajar descuidan a veces los estudios (trabajadora social, 2017).

El presupuesto ajustado contribuye a la segregación urbana de los colectivos migrantes que se ubican en zonas empobrecidas de la ciudad donde conforman redes colaborativas con otros migrantes. En estas zonas de segregación abundan los inmuebles subarrendados que generan condiciones de hacinamiento, riesgo de incendios, problemas de convivencia y desprotección de los hijos.

Un incendio que ocurrió este año por el motivo que en la misma habitación cocinan, tiene ahí la cocina, las camas, todo lo desarrollan en una pieza o dos piezas que ellos arriendan, se da esto del descuido porque los niños quedan solos (psicóloga, 2017).

Tengo que hacer las visitas domiciliarias y me conmueve porque he ingresado a algunas piezas y son lugares muy estrechos, porque ¿cómo tienes tus relaciones sexuales, que son lógicas, cómo las realizan, en qué momento? Y nos hemos preguntado qué cosas ven esos niños. A veces los niños escuchan, entonces ese es un tema preocupante (trabajadora social, 2017).

Como ellos arriendan piezas a veces puede ocurrir que como veinte personas ocupen un solo baño. Y eso sí nos ha pasado que a veces vienen los niños mal aseados, y comprendemos esta realidad, claro el baño a veces es unos minutos, un lavado de cara y así se vienen. Pero una se da cuenta cómo viven, con los turnos para el baño y que realmente es la única forma que tienen de desenvolverse (psicóloga, 2017). 


\section{Patrimonio cultural inmaterial}

El buen desempeño académico distingue a muchos estudiantes hijos de familias migrantes, quienes con frecuencia obtienen reconocimientos e incentivos por sus altos rendimientos en la celebración de las premiaciones escolares anuales. También sobresalen por el buen uso del lenguaje y el respeto que muestran hacia sus profesores.

Los destacados son muchos alumnos extranjeros, pocos chilenos, el mejor rendimiento generalmente eran de nueve cursos que se premiaban, siete extranjeros y dos chilenos. También acá premiaron mejor asistencia y también muchos alumnos extranjeros con mejor asistencia. Los alumnos extranjeros suman, aportan a la escuela (psicóloga, 2017).

Los agentes educativos describen a los apoderados migrantes y sus hijos como participativos y comprometidos con las actividades escolares. En los actos artísticos muestran desplante y carisma. Estos espacios les permiten expresarse con mayor libertad y sin miedo a la discriminación o la crítica por la diferencia.

Una profesora comentó que tenía tres apoderados colombianos, el resto era peruano, boliviano y chileno. Pero esos tres querían organizar algo para presentar sobre Colombia, aunque fueran solo tres, ellos estaban entusiasmados en traer una comida típica, con mostrar parte de su cultura, era algo que los entusiasmaba porque estaba abierta esa posibilidad (trabajadora social, 2017).

Desde pequeñitos su pronunciación, las palabras que usan, tienen un rico vocabulario. Lo que yo también una vez comenté es que tienen una facilidad para expresar las emociones. El acento es lo que los diferencia. Ellos a veces nos dicen palabras que nosotros no usamos y ellos mismos las explican, entonces no nos quedamos en la incomprensión (psicóloga, 2017).

El aporte cultural de los estudiantes migrantes enriquece el proceso educativo y nutre de saberes y tradiciones las diferentes asignaturas que imparten los profesores. En particular, la enseñanza de la lengua aymara genera un punto de encuentro debido al carácter transfronterizo de este pueblo originario, así la diversidad cultural se entiende como un valor indispensable en la formación de los estudiantes.

Sus aportes tienen que ver con los conocimientos previos que traen, el tema lingüístico, variantes lingüísticas, los temas culturales en relación a bailes y cantos. Conocimientos que aportan y que los dan a conocer con sus compañeros de curso. En el Machaq Mara (año nuevo aymara) se hacen varios bailes de Bolivia y de Perú (profesora, 2017).

Lo que más me gusta de mi práctica es transmitir la lengua, lo que más me llena es la transmisión de código lingüístico en sí, pero también la riqueza cultural que tiene ello, siempre me gusta. No es que estoy enseñando una palabra porque sí, no, esa palabra tiene su significado, tiene su semántica, algo por detrás. Casi todas las palabras en aymara, hay algunas palabras que son concepto de cultura, por ejemplo cuando vemos el Taypi, que es el equilibrio de la naturaleza, o el Suma Qamaña, que es el vivir bien, tantas palabras. Cada 
concepto de cada palabra habla de algo específico de la cultura que tiene que ver con principios, con valores, entonces yo mezclo el tema místico, el tema de valores, de cultura y me enriquece mucho la clase. Y lo puedo trabajar con ellos que son de otros países y si no lo saben se los enseño. Todo va a depender de la ética del profesor, cómo tú lo enfocas. ¿Cómo es en Colombia? ¿Con qué palabra nombran esto? Tú vas enfocando tu clase y vas integrando las formas de ver el mundo de estos niños, que es diferente (profesora, 2017).

$\mathrm{Al}$ reconocer e incorporar el patrimonio cultural diverso de sus estudiantes, los profesores también logran generar redes entre las distintas asignaturas, contribuyendo a un currículo educativo más flexible y abierto a la libre expresión de las diferencias y el fomento de la creatividad.

Se trabaja transversalmente, en educación física se vivencia mucho, en historia se trabaja todo el tema del territorio, se trabaja en la tecnología precolombina, todo eso se trabaja. El tema de los petroglifos, los territorios, los temas arqueológicos también se trabajan. Entonces ahí vas mezclando temas de cultura, lengua e historia. Algunos niños que vienen de Bolivia que han vivido en algunos pueblitos han visto petroglifos (profesora, 2017).

Ellos ahora hicieron bailes, incluso separaron un mismo curso para que programen dos bailes, entonces uno puede ser la cueca central y otro es la marinera, que es de Perú. Hay un baile que es afro, que tiene raíces de Arica pero es africano y también hay alumnos que van a bailar eso. Los zambos caporales que son del altiplano de aquí, en Chile se bailan los zambos, en las fiestas religiosas de nosotros en el norte, en Bolivia y en Perú. Y varios bailes que son de otros países. Así que tendremos niños de sus nacionalidades bailando quizás bailes propios de ellos, o chilenos bailando bailes que para nosotros son nuevos (psicóloga, 2017).

El trabajo de incluir la diversidad cultural en la práctica educativa tiene por objetivo potenciar la identidad cultural como una herramienta contra la exclusión social. Entender la riqueza de los orígenes para reafirmar a los estudiantes que enfrentan múltiples desafíos en el país de acogida es una excelente estrategia para estimular la resiliencia y el sentido de valía personal.

Trato de trabajar el que ellos tienen que tener autonomía de sus decisiones en temas culturales, del orgullo que tienen que tener de ser indígenas y de ser diferentes. Yo les trato de hacer entender a ellos que tienen que tener súper claro de dónde vienen, que tienen que cuidar de la naturaleza y de la lengua, y que lo tienen que aprender porque de esa forma se pueden defender (profesora, 2017).

Por tanto, el rol del agente educativo es fundamental para materializar las prácticas interculturales. Estas prácticas requieren compromiso, sensibilidad y perspectiva crítica de quienes las ejecutan, para desnaturalizar las dinámicas de exclusión que se normalizan en los contextos migratorios.

Hay algunas familias inmigrantes que se sorprendían cuando por ejemplo a principio de año todos los alumnos que estaban matriculados tenían derecho de un set de útiles escolares que el Alcalde lo repartió en las 
escuelas municipales y todos los niños inscritos de tal mes a tal mes iban a ser considerados, y después los que se van sumando les iba a llegar otra partida, pero a veces se sorprendían porque ellos vienen con la idea de que acá van a encontrar barreras, problemas, y que van a discriminar a sus hijos y que no les va tocar lo mismo que al resto (psicóloga, 2017).

A veces no tienen una mesa para hacer tareas, la mesa es para comer, para poner una tele y hacen sus tareas en las camas, pero acá les damos todas la comodidades, tienen un locker donde pueden guardar sus cuadernos, cada uno tiene un banco, tiene una silla, están cómodamente todos iguales, entonces nos llena de alegría que a veces con pocas cositas ellos se contentan tanto (psicóloga, 2017).

Yo me voy de vacaciones y voy a Tacna (ciudad peruana fronteriza) y por ejemplo compro algo para mí, algún libro en fin, pero siempre pensando en la escuela traigo estas cositas (-muestra unos juguetes comprados en Perú-). Cuando tú estás tan inmersa en lo que haces siempre estás pensando eso voy a llevar para la escuela, porque para el recreo vamos a arrasar, vamos a llamar la atención y que ellos disfruten (trabajado social, 2017).

En definitiva, facilitar los procesos de acogida de las familias migrantes, así como valorar las tradiciones y costumbres de las culturas de origen, debilita las fronteras y promueve iguales oportunidades de desarrollo desde la particularidad de cada estudiante. Es quizás en este ejercicio donde se encuentra la clave para romper con los estigmas y hacer de las escuelas verdaderas comunidades promotoras del desarrollo social.

Alumnos extranjeros y chilenos acá se mezclan, en el recreo uno hace fila para un juego y hay de todas las nacionalidades y todos se ríen, al fin los sentimientos son universales, todos los tenemos, las risas, ver las caras de felicidad de ellos cuando aprovechan sus recreos, se divierten, transpiran, porque lo dieron todo en esos recreos y los problemas que a veces hay detrás de ellos, en sus familias, eso como que queda de lado porque ellos en esos minutos están contentos (trabajadora social, 2017).

Para nosotros son todos iguales en derechos, pero tienen sus individualidades, sus particularidades y creo que todo esto es un aprendizaje para nosotros, cada entrevista con un apoderado, con un niño, vamos aprendiendo cosas nuevas que traen de sus culturas y todo esto a mí me aporta para la comprensión de ellos. Conocer sus formas de ver la vida, sus proyecciones, conocer cómo vivían sus familias, ha sido un aprendizaje para mí que también me ayuda a comprenderlos mejor. La visión que tengo de los alumnos migrantes es que aportan a nuestra alegría y suman al rendimiento, entonces yo creo que es bonito lo que se da acá en la escuela en relación a los chilenos con los inmigrantes. Es un aprendizaje que no termina, en la escuela cada día pasan cosas diferentes (psicóloga, 2017). 


\section{Conclusiones}

Latinoamérica es una de las regiones más violentas y desiguales del mundo. En este escenario el desarrollo macroeconómico que Chile ha sostenido en las últimas décadas, junto a su estabilidad institucional, lo han transformado en uno de los principales destinos para las familias migrantes latinoamericanas; sin embargo, los hallazgos de esta y otras investigaciones permiten identificar que al llegar al país, algunas familias encuentran múltiples contextos de segregación territorial y prácticas sociales que constituyen una geografía de la exclusión social.

Durante los procesos migratorios las estructuras familiares experimentan cambios de gran envergadura que pueden provocar desencuentros entre padres e hijos. En algunos casos la reunificación familiar implica un camino espinoso cuando los vínculos emocionales se han dañado tras años de distanciamiento. Para los padres es difícil recuperar la autoridad sobre sus hijos quienes la invalidan como una forma de protesta por los largos periodos de separación; esto genera, a su vez, una doble frustración, la de los padres que perciben que el esfuerzo de años de trabajo no es valorado por sus hijos, y la de los hijos, que resienten el tiempo que quedaron al cuidado de otros adultos.

A estas dificultades se suman las pautas del nuevo contexto sociocultural, que en ocasiones no se ajustan a las que traen desde sus países de origen. Los modelos de crianza de los hijos cambian de una sociedad a otra, así como los modos de relacionarse con los vecinos, los compañeros de trabajo o los pares en las escuelas, produciéndose entonces un choque cultural que puede estresar al sistema familiar y que implica un tiempo de ajuste para integrar las diferencias que los migrantes experimentan al ingresar a la cotidianidad de la sociedad receptora.

A nivel laboral, los migrantes enfrentan precarias condiciones marcadas por intensas jornadas y remuneraciones reducidas. Hace casi dos décadas el Censo del año 2002 ya revelaba que los migrantes intrarregionales sufrían en Chile una segmentación laboral que se limitaba a las áreas del trabajo doméstico, el comercio informal y la construcción (Martínez, 2003). Esta situación se ve reforzada en la frontera norte del país que constituye un espacio de circulación que permite a los migrantes ir y venir, favoreciendo la prevalencia de trabajos feminizados, orientados al cuidado y al servicio doméstico temporal (Tapia y Ramos, 2013).

En el ámbito barrial quedan en evidencia las condiciones de hacinamiento en las que viven las familias que se ubican en las zonas más empobrecidas de la ciudad. En algunos casos habitan viejas casonas que son subarrendadas entre varias familias de diversas nacionalidades, lo que incrementa las probabilidades de incendios y alimenta los problemas de convivencia. En otros casos, las familias migrantes se ubican en campamentos de extrema pobreza que pese al sostenido trabajo del Estado chileno y las organizaciones no gubernamentales, aún persisten en las áreas periféricas de las ciudades. Allí construyen viviendas de material ligero que no cuentan con servicios básicos, permisos, ni regularización, por ello entran en un constante conflicto con los gobiernos municipales y los vecinos de los sectores aledaños que reclaman por la creciente degradación de los barrios.

Estos antecedentes desalentadores ponen en evidencia la geografía de la exclusión social a nivel laboral y barrial. Así, se configura un ecosistema de segregación con límites territoriales determinados, pero también con prácticas sociales que perpetúan esta exclusión en el tiempo. Sin embargo, un punto de interés fundamental para esta 
investigación son las escuelas que se ubican dentro de esta geografía de exclusión social, pues pueden desafiarla al transformarse en espacios para el encuentro y la cooperación entre los actores que participan en ellas, es decir, el espacio escolar se puede presentar como el lugar propicio para dar cuenta de estas exclusiones y abordarlas desde un enfoque intercultural.

Al respecto Arias y Campos (2011, p. 11) señalan que se debe considerar al territorio como un actor articulador de su problemática y su solución. Por tanto, las barreras para la inclusión social no se limitan al ámbito material, sino que tienen relación además con los espacios de construcción del vínculo social y político. En consecuencia, las escuelas que gozan de una composición social heterogénea que interactúa, pueden estimular la equidad en la repartición de activos de capital social.

Ante la llegada de los estudiantes hijos de migrantes a las escuelas chilenas, el Estado ha establecido una serie de medidas para garantizar el derecho a la educación. Se estableció la entrega de un Identificador Provisorio Escolar (IPE) a los estudiantes que ingresen al sistema escolar sin visa o residencia definitiva. Con ello los estudiantes acceden a una matrícula definitiva aunque no posean cédula de identidad, manteniendo los beneficios de los programas de alimentación y de apoyo social.

Sin embargo, estas medidas deben avanzar también hacia la creación de programas educativos que promuevan el patrimonio cultural que las familias migrantes aportan a las escuelas. Esto se sustenta en los hallazgos de esta investigación que revelan como la comunidad educativa, al establecer espacios de diálogos y valoración de la diversidad cultural, puede avanzar en contrarrestar el sufrimiento social que provoca la exclusión. El objetivo no es caer en la idealización o victimización de las familias migrantes, más bien se trata de focalizar la atención en las posibilidades de desarrollo colectivo que aportan con su llegada, así como en la responsabilidad social de atender las necesidades que se producen en los procesos de movilidad poblacional. Con ello se podría garantizar una mejor acogida que promueva y respete los derechos humanos de las familias migrantes y que sirva de prevención de las consecuencias negativas asociadas a los procesos de segregación social.

En suma, el patrimonio cultural permite valorar los capitales culturales que aportan los estudiantes a sus comunidades educativas, visibilizando los orígenes comunes que poseen las sociedades latinoamericanas, así como la herencia del colonialismo del que emana el racismo que hasta el presente delimita la organización social en el continente. Al respecto, Huerta y Domínguez (2013, p. 12) promueven la incorporación de los patrimonios migrantes en el contexto educativo, señalando que los tránsitos e itinerarios que recorren los estudiantes y sus familias se transforman en otras tantas manifestaciones de la migración y de los senderos del arte, del patrimonio y de la educación artística.

Cabe destacar que la promoción de la inclusión social de los migrantes intrarregionales es de vital relevancia en la frontera norte de Chile, pues en ambos lados de la frontera los nacionalismos son alimentados por la incesante revisión de los añejos conflictos geopolíticos que definieron los límites territoriales entre Chile y sus países vecinos. Sin embargo, esta constante tensión política entre los Estados impide centrar la atención en el sufrimiento social que enfrentan los migrantes, quienes por un lado se ven obligados a dejar sus países de origen y por otro deben resistir las complejidades que emanan del proceso de recepción en el país de destino. Mientras los gobiernos ocupan su tiempo y valiosos recursos en sostener demandas, discursos de división y etnocentrismo, los migrantes deben sobrevivir en las geografías de la exclusión social. 
En este escenario los niños y niñas que ninguna responsabilidad tienen sobre las duras condiciones de vida en las que deben sobrevivir, terminan pagando las consecuencias de la ineficiente gestión del desarrollo social de sus países. Por ello, se debe pensar en las escuelas como escenarios de protección, inclusión y generación de oportunidades para el desarrollo vital de los estudiantes.

Podemos concluir que los migrantes intrarregionales escapan de la miseria, la violencia, la corrupción y la falta de oportunidades, pero llegan a un país que les impone nuevas barreras para alcanzar mejores condiciones de vida. Frente a esto, resulta interesante indagar en las experiencias de las escuelas que acogen a las familias migrantes, para visibilizar el compromiso y las estrategias que utilizan las comunidades educativas para contrarrestar la discriminación.

En definitiva, la migración intrarregional nos enfrenta al enorme desafío de romper las fronteras de la geografía de la exclusión social que permanecen enquistadas en las sociedades latinoamericanas, y con ello, acceder a la posibilidad de nuevos horizontes que nos permitan avanzar hacia un continente donde el migrar se entienda como una alternativa más y no como una estrategia obligada de supervivencia.

\section{Referencias}

Álvarez-Gayou, J. L. (2003). Cómo hacer investigación cualitativa. Fundamentos y metodología. Ciudad de México: Paidós Educador.

Arias, G. y Campos, F. (2011). ¿La geografía de la exclusión social coincide con la geografía de la política pública en Chile? Convergencia de los espacios de intervención para la regeneración de barrios y de escuelas con bajos resultados académicos en el Área Metropolitana de Santiago (AMs) de Chile. Revista Geográfica de América Central, 2(47E), 1-15.

Benedetti, A. y Salizzi, E. (2011). Frontera y movilidad, aproximaciones al caso argentino-boliviano. Revista do Centro de Educação e Letras, 13(1), 55-80.

Caba, S. y Rojas, M. (2014). Patrimonio migrante. Construcción social inclusiva e identitaria de la comunidad peruana en Santiago de Chile. Estudios Avanzados, (22), $86-115$.

Consejo Nacional de Infancia. (2015). Política nacional de niñez y adolescencia. Sistema integral de garantías de derechos de la niñez y adolescencia, 2015-2025. Santiago de Chile: Secretaría General de la Presidencia.

Departamento de Extranjería y Migración del Ministerio del Interior y Seguridad Pública. (2016). Migración en Chile 2005-2014. Recuperado de http://www.extranjeria.gob.cl/media/2016/02/Anuario-Estad\%C3\%ADstico-Nacional-Migración-en-Chile-2005-2014.pdf

Durand, J. (2013). América Latina en la espiral migratoria. En M. J. Sánchez e I. Serra (Coords.), Ellas se van. Mujeres migrantes en Estados Unidos y España (pp. 47- 86). Ciudad de México: Universidad Nacional Autónoma de México-Instituto de Investigaciones Sociales.

Guizardi, M. (2013). Inmigración, vivienda e integración social en España. Dilemas, retos y perspectivas. Ecléctica, Revista de Estudios Culturales, (2), 63-77. 
Huerta, R. y Domínguez, R. (2013). Patrimonios migrantes y educación artística. Los nuevos retos de la educación en patrimonio. Educación Artística Revista de Investigación, (4), 9-17.

Jiménez, M. (2008). Aproximación teórica de la exclusión social: Complejidad e imprecisión del término. Consecuencias para el ámbito educativo. Estudios Pedagógicos, 34(1), 173-186.

Jiménez, F. y Fardella, C. (2015). Diversidad y rol de la escuela. Discursos del profesorado en contextos educativos multiculturales en clave migratoria. Revista Mexicana de Investigación Educativa, 20(65), 419-441.

Joiko, S. y Vásquez, A. (2016). Acceso y elección escolar de familias migrantes en Chile: No tuve problemas porque la escuela es abierta, porque acepta muchas nacionalidades. Calidad en la educación, (45), 132-173. doi: https://dx.doi.org/10.4067/ S0718-45652016000200005

Marín, J. (2014). Hijos/as de inmigrantes en el norte de Chile: Hacia la construcción de una escuela intercultural. Santiago de Chile: Haz tu tesis en cultura. Recuperado de http://www.observatoriocultural.gob.cl/wp-content/uploads/2015/05/tesis_ jair_marin.pdf

Martínez, J. (2003). El encanto de los datos: Sociodemografía de la inmigración en Chile según el Censo de 2002. Santiago de Chile: Cepal.

Marxen, E. (2011). Diálogos entre arte y terapia. Barcelona: Gedisa.

Mondaca, C., Gajardo, Y., Muñoz, W., Sánchez, E. y Robledo, P. (2015). Estudiantes migrantes en la región de Arica y Parinacota. Caracterización, distribución y consideraciones generales. En M. Guizardi (Coord.), Las fronteras del transnacionalismo. Limites y desbordes de la experiencia migrante en el centro y norte de Chile (pp. 258- 280). Santiago de Chile: Universidad Católica del Norte, Ocho Libros.

Olivera, A. (2011). Patrimonio inmaterial, recurso turístico y espíritu de los territorios. Cuadernos de Turismo, (27), 663-677.

Pavez, I. (2012). Inmigración y racismo: experiencias de la niñez peruana en Santiago de Chile. Si Somos Americanos. Revista de Estudios Transfronterizos, 12(1), 75-99. doi: http://dx.doi.org/10.4067/S0719-09482012000100004

Riedemann, A. y Stefoni, C. (2015). Sobre el racismo, su negación, y las consecuencias para una educación anti-racista en la enseñanza secundaria chilena. Polis, Revista Latinoamericana, 14(42), 191-216. doi: http://dx.doi.org/10.4067/S071865682015000300010

Rojas, N. y Vicuña, J. T. (Eds.). (2014). Migración y trabajo. Estudio y propuesta para la inclusión sociolaboral de migrantes en Arica. Arica, Chile: Ciudadano Global oIm.

Sassone, S. M. y Mera, C. (2007). Barrios de migrantes, espacios interculturales: Coreanos y bolivianos en la ciudad de Buenos Aires. Ponencia presentada en xxvi Congreso de la Asociación Latinoamericana de Sociología, Guadalajara, México.

Soberanes, J. L. (2010). Igualdad, discriminación y tolerancia en México. Revista Mexicana de Derecho Constitucional, (22), 261-274.

Stefoni, C. (2002). Mujeres inmigrantes peruanas en Chile. Papeles de Población, 8(33), $118-145$. 
Tapia, M. (2014). Extranjeros fronterizos en las regiones extremas de Chile: entre migración y circulación. 1990-2014. En N. Rojas y J. T. Vicuña (Coords.), Migración y trabajo. Estudio y propuestas para la inclusión sociolaboral de migrantes en Arica (pp. 31-55). Arica, Chile: Ediciones Mensaje.

Tapia, M. y Ramos, R. (2013). Mujeres migrantes fronterizas en Tarapacá a principios del siglo xxi: El cruce de las fronteras y las redes de apoyo. Polis, Revista Latinoamericana, 12(35), 229-257. doi: https://dx.doi.org/10.4067/S071865682013000200011

Tijoux, M. E. (2011). Negando al "otro": el constante sufrimiento de los inmigrantes peruanos en Chile. En C. Stefoni (Ed.), Mujeres inmigrantes en Chile iMano de obra barata o trabajadoras con derechos? (pp. 17-42). Santiago de Chile: Ediciones Universidad Alberto Hurtado.

Tijoux, M. E. (2013). Las escuelas de la inmigración en la ciudad de Santiago: Elementos para una educación contra el racismo. Polis, 12(35), 287-307. doi: http:// dx.doi.org/10.4067/s0718-65682013000200013

Torres, F. (2011). La inserción de los inmigrantes. Luces y sombras de un proceso. Madrid, España: Talasa Ediciones.

Villaseñor, I. y Zolla, E. (2012). Del patrimonio cultural inmaterial o la patrimonialización de la cultura. Cultura y Representaciones Sociales, 6(12), 75-101.

\section{Entrevistas}

Trabajadora social. (2017). Entrevista a grupo focal/Entrevistador: Jair Marin-Alaniz [cinta de audio].

Psicóloga. (2017). Entrevista a grupo focal/Entrevistador: Jair Marin-Alaniz [cinta de audio].

Profesora. (2017). Entrevista a grupo focal/Entrevistador: Jair Marin-Alaniz [cinta de audio].

Jair Marín-Alaniz

Chileno. Magíster en Ciencias Sociales Aplicadas de la Universidad de Tarapacá. Egresado del Magíster en Patrimonio Intangible, Sociedad y Desarrollo Territorial de Universidad Arturo Prat. Líneas de investigación: migraciones internacionales, educación intercultural, urbanismo, patrimonio cultural. Entre sus más recientes publicaciones: Manual la infancia mundial en la escuela aumenta el capital cultural. Iquique, Chile: Universidad de Chile. 